\title{
Capítulo 11
}

\section{Crioulo, mulato e pardo: análise lexical das qualificações aos negros no Brasil oitocentista}

Mayara Aparecida Ribeiro de Almeida'

Amanda Moreira de Amorim²

\author{
Victor Antônio Sanches da \\ Silva Vaz \\ Maria Helena de Paula ${ }^{4}$
}

Resumo: É nosso objetivo apresentar uma breve análise lexical das qualificações "crioulo", "mulato" e "pardo", amplamente utilizadas no Brasil escravocrata para descrever os cativos ou seus descendentes. Para tanto, tomamos como corpus um livro de notas que se encontra sob os cuidados do Cartório do $2^{\circ}$ Officio - Tabelionato de Catalão, exarado entre 1861 e 1876, no qual há escrituras públicas de várias naturezas sobre os escravos, tais como: compra e venda, hipoteca, troca, liberdade, venda de partes e doação. Assim, ancorados nas lições da Lexicologia, buscamos compreender os sentidos com que essas unidades lexicais eram usadas no século XIX a partir da consulta a Moraes Silva (1813), Houaiss e Villar (2009) e Bluteau (1712-1728). Para compreender o contexto escravocrata, recorremos a Paiva (2014), Barros (2014), Guedes (2007), Pessoa (2013) e Fon-

1 Universidade Federal de Goiás - UFG. Regional Catalão, Unidade Acadêmica Especial de Letras e Linguística, Laboratório de Estudos do Léxico, Filologia e Sociolinguística (LALEFIL). Bolsista CAPES. Contato: may_aparecida20@hotmail.com

2 Universidade Federal de Goiás - UFG. Regional Catalão, Unidade Acadêmica Especial de Letras e Linguística, Laboratório de Estudos do Léxico, Filologia e Sociolinguística (LALEFIL). Bolsista FAPEG/CNPq. Contato: amandamoreiradeamorim@gmail.com

3 Universidade Federal de Goiás - UFG. Regional Catalão, Unidade Acadêmica Especial de Letras e Linguística, Laboratório de Estudos do Léxico, Filologia e Sociolinguística (LALEFIL). Bolsista CNPq. Contato: yumehideki8@gmail.com

4 Universidade Federal de Goiás - UFG. Regional Catalão, Unidade Acadêmica Especial de Letras e Linguística, Laboratório de Estudos do Léxico, Filologia e Sociolinguística (LALEFIL). Bolsista FAPEG (processo n 201510267000990). Contato: mhp.ufgcatalao@gmail.com 
seca (2007). Mais que designar a tonalidade da pele de escravos ou seus descendentes, tais lexias definiam a sua identidade social.

Palavras-chave: Escravidão. Léxico. Qualificações.

\section{Introdução}

O presente trabalho resulta dos diálogos estabelecidos entre as pesquisas "Nas trilhas dos manuscritos: estudo lexical sobre a escravidão negra em Catalão nos oitocentos" (PMEL/UFG-RC), "Edição semidiplomática e configurações da liberdade em cartas de liberdade na cidade de Catalão-GO (1861-1862)" (PIBICCAPES/FAPEG), "Configurações de alforria na cidade de Catalão: edição semidiplomática e estudo linguístico e histórico de Cartas de Liberdade em 1861 a 1876" (PIBIC/CNPq) e "Estudo da tipologia e gêneros de manuscritos sobre a escravidão em Goiás" (pós-doutorado/DLCV-USP), as quais forma motivadas pelo acervo digital do projeto "Em busca da memória perdida: estudos sobre a escravidão em Goiás”, coordenado pela Professora Maria Helena de Paula.

Essas pesquisas, embora com perspectivas distintas, têm como matéria o mesmo tipo de acervo documental, a saber: escrituras públicas relacionadas aos negros escravos. Assim, ao lidarmos com essa documentação identificamos uma gama de lexias utilizadas para caracterizar os cativos, o que nos impulsionou a olhá-las com mais afinco, motivo pelo qual propomos realizar esse estudo.

Amparados na perspectiva d estreita relação estabelecida entre o léxico, a cultura e a história de um povo acreditamos que a realização de um estudo lexical se faz muito relevante, visto que, tal como afirma Vilela, "o léxico é a parte da língua que primeiramente configura a realidade extralinguística e arquiva o saber linguístico duma comunidade. [...] O léxico é o repositório do saber linguístico e é ainda a janela através da qual o povo vê o mundo (VILELA, 1994, p. 6).

Para a realização desse estudo efetuamos, inicialmente, a edição semidiplomática dos documentos manuscritos, seguindo as "Normas para Transcrição de Documentos Manuscritos para a História do Português do Brasil", que foram publicadas em Megale e Toledo Neto (2005).

Em sequência, após a seleção das lexias a analisar, passamos à etapa de consulta aos dicionários. Utilizamos as seguintes obras lexicográficas: Moraes Silva (1813), Houaiss (2009) e Bluteau (1712-1728). Buscando ainda, conhecer o contexto em que essas lexias foram empregadas e visando a uma análise que contemplasse também fatos históricos, recorremos aos autores Paiva (2014), Barros (2014), Guedes (2007), Pessoa (2013) e Fonseca (2007).

Feito isso, buscamos observar o contexto de uso em que as lexias foram empregadas a fim de identificar com quais sentidos foram utilizadas na caracteri- 
zação dos negros escravos. Ao final dessas etapas, tivemos condições de elaborar uma análise dizendo dos sentidos com que essas lexias foram empregadas no século XIX.

\section{A necessidade das qualificações}

Em observância aos documentos manuscritos que utilizamos em nossas pesquisas, identificamos uma série de lexias dispostas ao lado do nome dos escravos, levando-nos a conjecturar em um primeiro momento que se tratavam do sobrenome dos cativos. Em uma leitura mais acurada, notamos que se referem a caracterizações étnicas e/ou cromáticas dos escravos.

É necessário frisar, entretanto, que estas atribuições étnicas nem sempre seguiam um modelo de classificação que seguisse de fato a forma como os negros africanos eram caracterizados etnicamente em suas terras de origem, conforme pode ser observado no seguinte excerto.

Nesse contexto, não é de se estranhar que administradores coloniais do trabalho escravo também tivessem de recorrer à moldagem de novas diferenças negras, em nada ou muito pouco relacionadas com as antigas etnias africanas. Precisavam saber, por exemplo, quais tipos de escravos eram mais adaptáveis ao trabalho na agricultura, ao trabalho nas minas, aos serviços domésticos, e assim por diante. Ajudar-lhes-ia conhecer não tanto as etnias originais dos negros, mas o tipo de trabalho com os quais estiveram acostumados na África, o tipo de vegetação e clima com os quais lidavam ancestralmente, e talvez conhecer algo do seu potencial de rebelião ou fuga (BARROS, 2014, p. 80).

Segundo Barros (2014) as tentativas de se atribuir uma etnia/nação específica aos escravos, com base em suas aptidões, surgiram por questões práticas que buscavam a otimização do trabalho escravo. Dessa forma, a cada etnia eram destinados serviços distintos, os quais representavam a percepção ou imaginação que os administradores do trabalho colonial detinham sobre as habilidades dos africanos. Esta prática passou a ser usada com frequência quando os colonizadores tiveram interesse por questões de censo demográfico dos escravos e pela necessidade de especificar quais atividades os escravos africanos exerciam ou, ainda, em quais estes pudessem se adequar.

O referido autor acrescenta que estas diferenciações se davam em função dos circuitos de exportação, isto é, dependendo do local dos portos de onde saíam. Dessa forma, era possível observar dois tipos de etnias, a etnia de origem e a 
etnia do tráfico. A primeira correspondia à origem real dos escravos, enquanto a segunda tratava sobre a localização geográfica dos portos do tráfico negreiro.

Primeiramente, estas caracterizações informavam as regiões de onde os escravos africanos provinham, identificando junto a isso as principais características dos negros e para quais serviços estes eram mais indicados. Exemplos: Minas, Angola, Moçambique, Benguela, entre outros. Com o tempo, novas realidades exigiram novas nomeações. Em território colonial, surgiram novas diferenciações entre os escravos, dividindo-os dali por diante em três grupos: os africanos, os crioulos e os mestiços.

E essas nomeações são aqui chamadas de "qualidades" em conformidade com a postura teórica defendida por Paiva (2014) em sua tese "Dar nome ao novo: uma história lexical da ibero-América, entre os séculos XVI e XVIII (as dinâmicas de mestiçagens e o mundo do trabalho)". Segundo esse autor, essas "qualidades" tinham a função de diferenciar, hierarquizar e classificar os indivíduos por meio de origem familiar, traços fenótipos (cor e características do cabelo, nariz e boca) e percepções sociais. Paiva (2014) ressalta, ainda, que essas percepções eram muito heterogêneas porque dependiam do olhar individual de cada pessoa e das conveniências, o que permitia que uma pessoa pudesse ter suas qualificações alteradas ao longo dos anos. Assim, dentre essas qualificações, lançamos nosso olhar sobre os crioulos e os mestiços (especificadas nas unidades léxicas mulato e pardo).

\subsection{A lexia "crioulo"}

A lexia "crioulo", segundo Barros (2014), surge para referenciar a descendência escrava que nasce no Brasil. Em consulta ao dicionário Vocabulario Portuguez e Latino de Bluteau (1712-1728), encontramos que crioulo corresponde ao "escravo, que nasceo na casa do seu senhor". Em Houaiss e Villar (2009), observa-se a seguinte definição "que ou quem nasceu escravo nos países sul-americanos, p. opos. a quem já chegou da África com essa destinação”.

Em acordo com essa definição, Paiva (2014) diz que o termo crioulo/criollo era utilizado para qualificar aqueles que nasceram na América e que eram filhos de africanos, podendo ser usado ainda para identificar os filhos de africanos com crioulos.

Trazendo um novo sentido para essa lexia, Barros (2014) aponta que crioulo referia-se à nação do escravo, mas não em seu sentido original, uma vez que os crioulos não compartilhavam de uma mesma cultura, pois provinham de regiões e países diferentes. Entendemos, então, que nação aqui era empregado apenas para dizer que esses escravos nasceram em território americano. 
Cabe elucidarmos as demarcações sociais advindas com essas qualificações. Barros (2014) aponta que essa nova realidade trouxe consigo situações conflitantes porquanto estabeleceu-se uma hierarquia ideológica tangente aos escravos em que os crioulos se superpunham aos africanos, por terem nascido em território brasileiro, enquanto que os mestiços usufruíam de uma posição mais alta do que os crioulos, por serem fruto da miscigenação de negros com brancos, ou seja, por se aproximarem mais da cor branca, entendida nesse contexto histórico como a cor dos civilizados.

Ante essa breve incursão identificamos que o termo "crioulo" poderia ser utilizado com três sentidos distintos, conforme se observa no seguinte quadro.

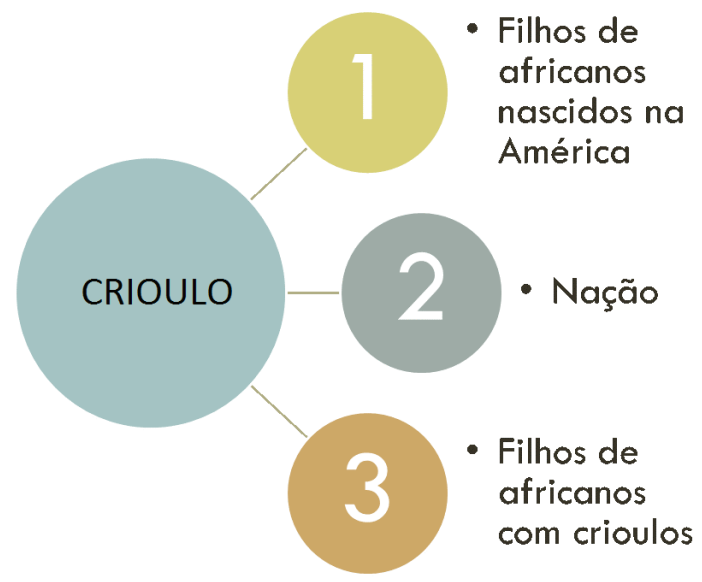

Figura 1 Sentidos da lexia "crioulo".

Fonte: Elaborado pelos autores (2016).

Para o primeiro sentido, em que o crioulo seria aquele que nasceu no continente americano e cujos pais são de origem africana, não encontramos informações suficientes para essa afirmação, visto que as filiações dos escravos não eram dispostas com muita frequência no acervo documental a que nos detivemos. Geralmente, são apresentadas informações sucintas como o nome, a qualificação do escravo e a sua idade, conforme se observa no trecho da escritura de compra e venda do escravo Bernardo: "o escravo Bernardo, crioulo, de idade de I vinte trez para vinte quatro annos. (fólio 216v, linhas 25 e 26)" (Doc 216r a 217r), em que o escravo Bernardo poderia se enquadrar em qualquer uma dessas definições, visto a falta de informações.

Com relação ao termo crioulo empregado unicamente no sentido de nação, isto é, para dizer daquele que nasceu na condição de escravo no território americano, apresentamos o seguinte fragmento: "escrava I de nome Maria, crioula, parda, de idade I de trinta dous annos mais ou menos. (fólio 210v, linhas 22-24)" retirado da escritura de liberdade da escrava Maria. Neste caso, temos certeza 
dessa acepção uma vez que ao lado da lexia crioula está disposta a lexia parda que se refere à ascendência da escrava, conforme discutimos nas seções seguintes.

Por fim, para exemplificar crioulo como indicador da filiação do escravo, em que este é filho de crioulo com africana ou vice-versa, apresentamos o trecho extraído de uma escritura de hipoteca de "uma escrava I de nome Marianna, Crioulla, idade I de vente e cinco annos pouco mais lou menos, e um crioulinho de nome $\mid$ Adaõ filho da mesma, com qua $=\|139 \mathrm{v}\|$ quatro annos de idade pouco mais I ou menos" (fólio 139 recto e verso, linhas 2-8). Conforme se vê, mãe e filhos são qualificados como crioulos, demonstrando que esta lexia era utilizada ainda para indicar as primeiras descendências dos crioulos.

\subsection{A lexia "mulato"}

A nomeação de mulato é utilizada de forma unânime como uma fusão étnica entre um indivíduo de pele escura com outro de pele clara, mais comumente no nosso país, entre negros e brancos. Tal lexia, encontrada massivamente em cartas de venda ou de alforria, se tratava de um termo recorrente no período da escravidão. Ainda é utilizada por brasileiros na atualidade, porém, em menor escala. Houaiss e Villar (2009) trazem uma definição em que "mulato é aquele que não apresenta traços raciais definidos", e ainda ressaltam que a mestiçagem que os caracterizava pode se dar tanto pela parte de negros, quando de indígenas. Nas discussões apresentadas por Paiva (2014), consta que mulato, no Peru, era utilizado como sinônimo de zambo ou zambaigo, filhos de negros com índios, ou negros com europeus, o que prova como esse termo se diferencia por conta da variação regional.

Segundo Barros (2014), em seu livro "A construção social da cor: diferença e desigualdade na formação da sociedade brasileira", o mulato usou de seu tom de pele mais claro por conta de descendência europeia, para encontrar uma posição hegemônica de maior privilégio que seus parentes africanos e crioulos. Barros também cita os ditos do cronista do século XVIII Antonil, nos quais ele afirma que "o Brasil he Inferno dos negros, Purgatório dos brancos, e Paraíso dos mulatos e das mulatas". Isso se explicaria pelo fato de os negros terem sido arrancados de sua terra mãe para prestarem serviços forçados na América, se submetendo a toda sorte de torturas físicas e psicológicas e porque os portugueses terem deixado sua terra para se dirigirem ao inóspito continente a fim de acumularem suficiente riqueza e retornarem à terra mãe. Enquanto isso, os mulatos, que estão no entremeio desses dois mundos e não tiveram que deixar seus próprios lares, já estão exatamente em seu habitat natural, pois são o resultado de série de ocorridos dramáticos que convergiram nestas terras para um grupo étnico inédito surgido no Novo Mundo.

No entanto, se se trata de um Paraíso ou não aos mulatos, depende do ponto de vista, pois não foram todos que tiveram a fortuna de terem sua filiação reconhecida 
por um senhor português e viver sua vida sem ter de carregar nas costas o peso da escravidão, sobretudo porque, como o próprio Barros (2014) menciona, os mulatos não deixaram de sofrer preconceito, não só por europeus que acreditavam que eles fossem a consequência da contaminação de sua raça, mas também pelos próprios negros (geralmente crioulos), que se sentiam desprivilegiados em relação a eles.

Ainda segundo Barros (2014), qualidade mulata é muito profunda e abrangente. Posição intermediária entre branco e preto é uma acepção um pouco rasa, já que entre essas duas cores podem existir inúmeras variações, algumas mais claras e outras mais escuras. Diante disso, encontram-se o que podemos chamar de subclassificações de mulato, normalmente a escura era chamada de cabra e a clara de parda, além de várias outras. Já de acordo com Guedes (2007), mulato tratava-se de um sinônimo de pardo, no entanto, diferente do segundo, este era utilizado com o objetivo de depreciar o indivíduo.

Esse caráter pejorativo dado ao termo mulato é elucidado por Pessoa (2013). Segundo ele, por conta da inclinação de algumas pessoas em caluniar mulatos que viviam sob a proteção de alguém provido de honrarias, normalmente esse alguém sendo seu pai (um branco senhor de escravos), isso permitia a essa camada popular vista culturalmente como inferior a desfrutar de regalias normalmente direcionadas aos brancos. De acordo com a lógica dessas pessoas, o mulato afortunado que conseguia ascender socialmente não se encontrava em sua devida posição.

Separamos esse trecho de uma carta de alforria, onde nota-se a presença da classificação mulato "de úm escravo de nome Joaõ Mulato, filho I de Julianna escrava que foi de minha fal I licida Maĩ Dona Felicia Maria do Esperito I Santo, cuja parte me coube porherança I da mesma" (fólio 233v, linhas 5-9). Normalmente a descrição do escravo é apresentada antes de seu nome de batismo, mas neste fólio em específico percebemos que a característica étnica de João foi elevada à categoria de sobrenome. Ele é identificado como sendo o filho da falecida escrava do senhor; todavia, em se tratando de um mulato, o pai seria provavelmente o próprio homem que lhe concedeu a liberdade, algum outro branco não identificado, ou mesmo um mulato/pardo cativo ou liberto.

Pessoa (2013) afirma com propriedade que o mulato se encaixa em um local de intersecção entre a liberdade e o cativeiro. Isso se explica, porque de forma geral, todo aquele nascido de escrava era, como resultado, também um escravo. No entanto, o número de mulatos libertos era significativo, seja tal emancipação concedida logo cedo em uma pia batismal, ou mais tarde, quando era comprado ou alforriado pelo próprio pai ou outro. Mesmo aqueles que não eram de fato libertos desfrutavam de certo favoritismo ou proteção paterna.

Diante disso, chegamos a três definições identificadas da lexia mulato. Começando pela mais popularmente encontrada e reconhecida, a de se tratar do produto de uma mistura étnica, cujas etnias variam de acordo com o contexto 
regional, ainda que em nossa realidade fosse mais comum ser entre brancos e negros. A segunda configura uma variação de tom, dificultando a classificação precisa. A terceira diz respeito ao fato de disporem de uma posição social incerta, pois a maioria nasceu sobre uma linha tênue entre estar livre e escravizada, alguns sendo mais afortunados que outros.

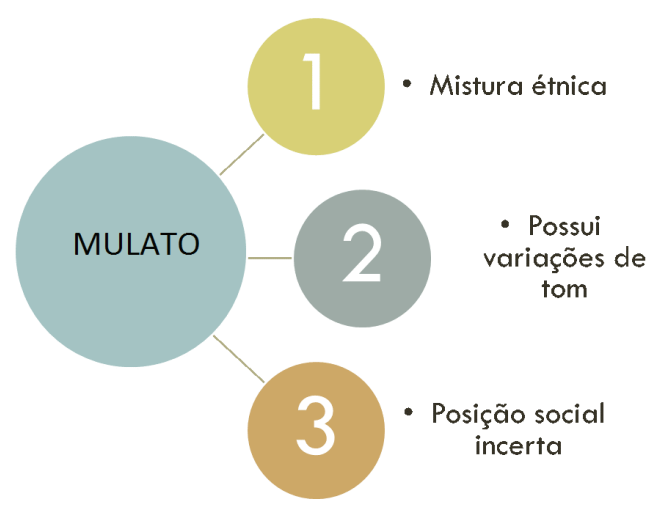

Figura 2 Sentidos da lexia "mulato".

Fonte: Elaborado pelos autores (2016).

\subsection{A lexia "pardo"}

Abordamos, anteriormente, as dinâmicas de sentido das lexias crioulo e mulato com as acepções encontradas. Voltaremos, agora, nosso olhar para a unidade lexical pardo, utilizada para nomear escravos e seus descendentes, nascidos livres ou não, durante o período escravocrata brasileiro.

De acordo com Paiva (2014), o vocábulo pardo, bem como mulato, já era empregado na Península Ibérica e em outras regiões ocupadas por espanhóis e portugueses. Dentre as duas lexias, o autor indica que pardo aparenta ter sido utilizada com maior frequência e em contextos anteriores a mulato, com ocorrências ainda no século XII, em Portugal, designando pele de animal. Em 1500, com a chegada dos lusitanos em terras brasileiras, Pero Vaz de Caminha, em sua carta enviada ao rei D. Manuel I, descreveu como pardos os homens que já ocupavam estas terras, associando sua cor à mesma tonalidade dos papagaios.

No século XVI, encontramos registros de pardo como indicador de "qualidade" caracterizando misturas entre negros, crioulos, mulatos ou zambos com brancos ou índios. Percebemos, então, como o contexto em que a lexia era empregada poderia ser amplo, visto que denotava a miscigenação entre grupos distintos. Ao mesmo tempo, representava a cor da pele, com "variações de época para época e de região para região e mesmo na mesma época e na mesma região” (PAIVA, 2014, p. 198). 
Quanto à cor da pele, os dicionários antigos Bluteau (1712-1728) e Moraes Silva (1813) apresentam a mesma definição para pardo, classificando-a como a cor entre branco e preto, como a do pássaro pardal. Esta acepção estendeuse ao longo dos anos, uma vez que no dicionário Houaiss (2009) encontramos pardo referindo-se ao que é "de cor escura, entre o branco e o preto". Com isso, compreendemos que pardo era utilizado para indicar escravos de cor mais clara - "branco sujo, escurecido" (HOUAISS; VILLAR, 2009) -, a qual derivava do processo de miscigenação entre os de pele mais escura e os de mais clara, resultando em um branqueamento daqueles que ainda serviam à escravidão.

Exemplificando pardo como indicador de cor da pele, apresentamos o trecho extraído do documento manuscrito presente nos fólios $244 \mathrm{r}$ a $244 \mathrm{v}$, uma escritura de liberdade: "escravinha de nome Augusta crioula | parda, de idade de trez annos mais ou I menos, a qual é filha natural de I sua escrava de nome Melchiades" (fólio $244 \mathrm{v}$, linhas 20-23, grifo nosso). Neste excerto, a lexia crioula marca a qualidade da escravinha Augusta, indicando que a mesma poderia ser filha de africanos, nascida na América; ter nascido na condição de escrava, em um país sul-americano, nesse caso o Brasil; ou ser filha de mãe ou pai africano com um parceiro já crioulo. A unidade lexical parda complementa a qualidade crioula, indicando que, além de nascer em solo brasileiro sob uma das condições supraditas, Augusta ainda possuía o tom de pele mais claro.

No século XVIII, pardo passa por um deslocamento de sentido, caracterizando, então, o campo "condições". Em uma sociedade escravista ativa, a mudança da condição social de certos indivíduos era comum, como a nova condição de forro para qual passava um escravo ao ganhar sua alforria. Neste contexto, pardo passou a indicar um afastamento do passado escravo, como aponta Guedes (2007), baseando-se em diversos autores. Nessa nova concepção, pardo se referia aos nascidos de escravos libertos, ou seja, a primeira geração de descendentes de escravos nascida livre no Brasil.

Sob essa ótica, cunhou-se a categoria social pardo livre, que expressa a condição daqueles que nasceram livres da descendência africana, ainda que não fossem mestiços, o que os afastava ainda mais dos reflexos da vida em cativeiro. Essa nova geração caminhava a passos lentos para esquivar-se das marcas deixadas pela escravidão, lutando contra as restrições civis que este passado implicava.

Essa nova significação atribuída à lexia pode ser entendida como um dos principais traços do processo de miscigenação e branqueamento que ocorreu no interior da comunidade escrava. Além de indicar a condição de nascido livre, pardo passou a ser utilizado como um indicador social, provocando uma hierarquização interna entre os forros e seus descendentes, pois como cor da pele, o pardo aproximava-se mais do branco, modelo ideal a ser seguido na época em questão. 
Visando a exemplificar a utilização da lexia pardo para identificar os descendentes de escravos nascidos livres no Brasil, elaboramos um levantamento de 208 registros de batismo extraídos do Livro de Registro de Batismo de 1871 a 1885. Desses registros, 87 atribuíam às crianças nenhuma qualidade, apenas as identificavam como forros a partir daquele ato. Os 121 registros restantes categorizavam os ingênuos, dividindo-os em pardos - com 74 ocorrências -, pretos - 45 ocorrências -, e crioulos - apenas duas ocorrências. A partir desse inventário, inferimos que, ainda que não fosse unânime, o uso de pardo para indicar os filhos de escravos nascidos no Brasil ocorria com frequência.

Chamou-nos atenção outra definição encontrada no Vocabulario Portuguez e Latino, de Bluteau (1712-1728), a qual define "homem pardo. Vid. mulato". Pessoa (2013) destaca que pardo e mulato descrevem o mesmo tipo humano, e que suas diferenças se dão no âmbito social.

Fruto da miscigenação, tanto pardos quanto mulatos são filhos de brancos com negros, possuidores de um tom de pele entre o branco e o preto. De acordo com Pessoa (2013), o que determinava a utilização de determinado identificador era o comportamento do sujeito em sociedade. Aqueles que se comportassem de modo reprovável seriam classificados como mulatos, enquanto os que se comportavam de modo digno seriam qualificados como pardos. O autor também elucida que pardo era preferencialmente utilizado em documentações oficiais e formais, devido ao peso pejorativo que mulato continha. Por este motivo, não nos foi possível localizar exemplos para demonstrar o uso de mulato e pardo como classificador de comportamento social, visto que o uso de pardo era preposto ao de mulato.

Em suma, reunimos abaixo as três significações encontradas por nós para a lexia pardo: a primeira para designar uma pigmentação de pele mais clara, entre branco e preto; a segunda para indicar uma nova geração de descendentes de escravos nascidos livres no Brasil e a terceira como um diferenciador social, caracterizando os filhos de brancos com negros de boa índole e comportamento digno.

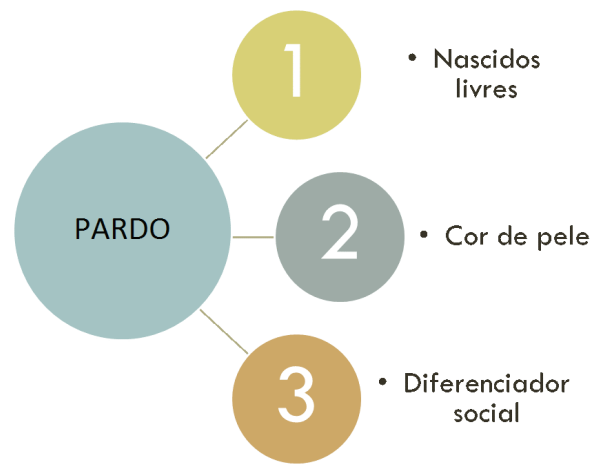

Figura 3 Sentidos da lexia "pardo".

Fonte: Elaborado pelos autores (2016). 


\section{Conclusão}

Com todas as multiplicidades de abordagem teórica e de acepção, seja de uso nos documentos analisados, seja nos dicionários consultados, depreendemos que estas qualificações analisadas, inicialmente como um simples selo de origem ou uma pequena marca diferenciadora de tonalidades, notavelmente com o tempo de uso (ou o ângulo diferente pelo qual passaram a ser observadas), evoluíram para tornar concepções muito mais complexas.

Foi previsível e uníssono em nossas pesquisas o quão intrincadas essas lexias estão com todo o contexto socioideológico do período escravocrata, definindo a posição hegemônica dos indivíduos perante outros mancípios e perante a sociedade como um todo. Ademais, para além de apenas uma escala hierárquica simbólica, a classificação que lhes era declarada estabelecia a forma como viveriam até o fim de seus dias, ou como as pessoas à sua volta permitiriam que vivessem. Tais lexias carregavam o peso lúgubre de serem crioulos, mulatos e pardos e, por décadas a fio, pelos que herdaram essa condição.

Como visto, muito mais do que um mero designador da tonalidade da pele de escravos - ou descendentes deles - tais lexias carregam um intrincado contexto social que, dependendo da época e do meio geral ou particular em que ocorria a sua utilização, tendiam a definir identidades ou a forma como esses indivíduos eram vistos e tratados por aqueles de seu convívio.

\section{Referências}

ANDRADE, Carlos Antonio de. Livro de Notas do $2^{\circ}$. Tabelliaõ (1886-1887). Cartório do $2^{\circ}$. Ofício - Tabelionato de Catalão: Catalão-GO, 2007.

BARROS, José D'Assumção. A construção social da cor: diferença e desigualdades na formação da sociedade brasileira. Petrópólis/RJ: Vozes, 2014.

BLUTEAU, Raphael. Vocabulario portuguez \& latino: aulico, anatomico, rchitectonico... Coimbra: Collegio das Artes da Companhia de Jesus, 1712 - 1728.8 v. Disponível em: <http://www.brasiliana.usp.br/dicionario/edicao/1 >. Acesso em: 10 maio 2015.

FONSECA, Marcus Vinícius. Pretos, pardos, crioulos e cabras nas escolas mineiras do século XIX. 2007. 256 fls. Tese (Doutorado) - Faculdade de Educação, Universidade de São Paulo, São Paulo, 2007.

GUEDES, Roberto. Escravidão e cor nos censos de Porto Feliz (São Paulo, Século XIX). Cadernos de Ciências Humanas - Especiaria. v. 10, n.18, jul. - dez. 
2007, p. 489-518. Disponível em: www.uesc.br/revistas/especiarias/ed18/5_ roberto_guedes.pdf. Acesso em: 10 abr. 2016.

HOUAISS, Antônio; VILLAR, Mauro de Salles. Dicionário Houaiss da Língua Portuguesa. Rio de Janeiro: Objetiva, 2009.

Livro de Notas do $2^{\circ}$. Tabelliaõ (1861-1876). Cartório do $2^{\circ}$. Ofício - Tabelionato de Catalão: Catalão-GO, 2007.

MEGALE, Heitor; TOLEDO NETO, Sílvio de Almeida. Por minha letra e sinal: Documentos do ouro do século XVII. Cotia, SP: Ateliê Editorial, 2005.

MORAES SILVA, Antonio. Diccionario da lingua portugueza. 2. ed. Lisboa: Typographia Lacerdina, [1789] 1813. 2 tomos. Disponível em: <http://www. brasiliana.usp.br/dicionario/edicao/1>. Acesso em: 10 maio 2015.

PAIVA, Eduardo França. Dar nome ao novo: uma história lexical das Américas portuguesa e espanhola, entre os séculos XVI e XVIII (as dinâmicas de mestiçagem e o mundo do trabalho). Belo Horizonte: FAFICH/UFMG, 2014. (Tese, apresentada a banca para o concurso de Professor Titular de História do Brasil).

PESSOA, Raimundo Agnelo Soares. Gente sem sorte: a invenção dos mulatos no Brasil Colonial. Goiânia: Editora UFG, 2013.

VILELA, Mário. Estudos de Lexicologia do Português. Coimbra: Almedina, 1994. 